\title{
The effect of newly initiated exercise training on dynamic thiol / disulphide homeostasis in sedentary obese adults
}

\author{
HAKIM CELIK ${ }^{1}$, TUGBA KILIC ${ }^{2}$, DAVUT S. KAPLAN ${ }^{2}$, MEHMET A. EREN ${ }^{3}$, \\ OZCAN EREL ${ }^{4}$, ALI Z. KARAKILCIK ${ }^{1}$ and CAHIT BAGCI ${ }^{5}$
}

\author{
${ }^{1}$ Department of Physiology, Medical Faculty, Harran University, 63000 Sanliurfa, Turkey \\ ${ }^{2}$ Department of Physiology, Medical Faculty, Gaziantep University, 27000 Gaziantep, Turkey \\ ${ }^{3}$ Department of Endocrinology, Medical Faculty, Harran University, 63000 Sanliurfa, Turkey \\ ${ }^{4}$ Department of Clinical Biochemistry, Medical Faculty, Yildirim Beyazit University, 6000 Ankara, Turkey \\ ${ }^{5}$ Department of Physiology, Medical Faculty, Sakarya University, 54050 Sakarya, Turkey
}

Manuscript received on September 10, 2018; accepted for publication on December 4, 2018

\begin{abstract}
How to cite: CELIK H, KILIC T, KAPLAN DS, EREN MA, EREL O, KARAKILCIK AZ AND BAGCI C. 2019. The effect of newly initiated exercise training on dynamic thiol / disulphide homeostasis in sedentary obese adults. An Acad Bras Cienc 91: e20180930. DOI 10.1590/0001-3765201920180930.
\end{abstract}

\begin{abstract}
We studied dynamic thiol/disulphide homeostasis, an indicator of oxidative stress, to investigate the effects of newly initiated exercise training on sedentary obese adults. Seventeen sedentary obese adults and 15 normal-weight controls were included in the sample for this study. The obese adults were given a physical exercise training program that lasted twelve weeks. Before and after the exercise training program, blood samples were collected, and serum thiol/disulphide parameters were measured by using a novel technique. Before the start of the exercise training, it was observed that thiol/disulphide homeostasis was impaired, and this impairment was positively correlated with body mass index in sedentary obese adults because of the higher reactive oxygen species production in adipose tissue. However, while the obese participants' body mass index significantly decreased, the thiol/disulphide homeostasis parameters in the obese adults did not change over time as calculated at the baseline and compared to the calculation after the twelve weeks of exercise training. Despite a decrease in body mass index that occurred after the twelve weeks of exercise training, there was a lack of improvement in the obesity-induced impairment of thiol/disulphide homeostasis, which suggests that a newly initiated exercise training program may lead to oxidative stress.
\end{abstract}

Key words: exercise, obesity, oxidative stress, thiol / disulphide homeostasis.

\section{INTRODUCTION}

Along with the rise of technological advancements in industry, there has been an increase in the number of people who have a sedentary lifestyle. Subsequently, the incidence of obesity has

Correspondence to: Hakim Celik

E-mail: hakimcell@gmail.com

ORCid: https://orcid.org/0000-0002-7565-3394 increased worldwide (Da Silva Medeiros et al. 2015). Obesity, one of the most important health problems of the 21 st century, is accepted as an important underlying factor in the pathogenesis of many diseases, such as metabolic syndromes, type 2 diabetes, cardiovascular diseases, hypertension, sleep disorders and several forms of cancer (Manna and Jain 2015, Matsuda and Shimomura 2013). In 
addition, it has been found that obesity is associated with chronic systemic inflammation of the adipose tissue and that this inflammation is associated with oxidative stress (OS) (Marseglia et al. 2015, Matsuda and Shimomura 2013).

OS is an imbalance between the oxidants and antioxidants, which is caused by an increase of reactive oxygen species (ROS) and/or a decrease of the antioxidant defense systems in organisms (Bianchi and Ribisl 2015, Huang et al. 2015, Rupérez et al. 2014). ROS have potent oxidative effects on proteins, lipids and DNA, which result in an impairment of various cellular functions (Ates et al. 2015, Matsuda and Shimomura 2013). The antioxidant defense system including enzymatic (e.g., superoxide dismutase, glutathione reductase, glutathione peroxidase, catalase, heme oxygenase-1 and paraoxonase) and non-enzymatic (e.g., polyphenols, some vitamins, glutathione, carotenoids, and selenium) antioxidants maintains ROS homeostasis in the cells (Matsuda and Shimomura 2013, Rupérez et al. 2014). When the production of ROS exceeds the antioxidant defense capacity, which is a state defined as OS, many pathological conditions such as atherosclerosis, aging, cancer, metabolic syndrome, obesity and other inflammatory diseases emerge (Kundi et al. 2015, Manna and Jain 2015, Rupérez et al. 2014). Therefore, the stability of the oxidants-antioxidants balance is a vital matter for the overall health of organisms.

Although overweight and obese patients are recommended to lose weight, exercise training causes OS depending on the type and intensity of the physical activity. The augmentation in muscle activity during exercise training increases oxygen consumption and mitochondrial electron transport chain activity for energy generation, which results in a high amount of ROS production (Saiki et al. 2001, Vincent et al. 2005). Several studies have indicated that acute and intense exercise increases oxygen consumption, energy expenditure ROS production and lipid peroxidation (Emami et al. 2016, Kruk and Duchnik 2014, Vincent et al. 2004). Furthermore, when physical exercise is performed at the same duration and intensity, it is claimed that obese and overweight people have more oxygen consumption and energy expenditure than normalweight individuals (Vincent et al. 2004). However, several other studies have indicated that regular and moderate-intensity exercise training can decrease oxidative damage to biomolecules such as lipids, proteins and DNA and can also induce production of enzymatic and non-enzymatic antioxidants (Duggan et al. 2016, Veskoukis et al. 2016).

Thiols, which contain a functional group of sulfhydryls, are potent antioxidant molecules that preserve the organism from the destructive influences of OS damage (Hanikoglu et al. 2016). When OS develops, thiol groups in albumin, cysteine, homocysteine, glutathione, as well as other proteins are converted to disulphides. Subsequently, the disulphide bridges can be reversibly reduced to thiol groups by certain antioxidants, and thus, a dynamic thiol/disulphide homeostasis (TDH) is sustained (Simsek et al. 2016). In living organisms, TDH has important functions in relation to OS, such as the regulation of enzymatic reactions, the antioxidant defense system, detoxification and apoptosis (Simsek et al. 2016, Zubarioglu et al. 2017). Investigations of the TDH parameters have been performed at the initiation and along the progression of many diseases such as hypertension (Ates et al. 2015), diabetes mellitus (Ates et al. 2016), cardiovascular diseases (Elmas et al. 2017), migraines (Gumusyayla et al. 2016) and childhood obesity (Elmas et al. 2017) and a close relationship has been detected between OS and an impairedTDH.

As mentioned in previous studies, both obesity and physical exercise cause an increased level of OS, independent of each other. However, it is unclear whether OS level changes in obese adults due to a newly initiated exercise training program 
to lose weight. Therefore, we hypothesized that a newly initiated exercise training program in sedentary obese adults could increase OS, despite a significant decrease in BMI. To evaluate the effects of the exercise training program, we aimed to investigate TDH parameters, an indicator of OS, in sedentary obese adults.

\section{MATERIALS AND METHODS}

\section{SUBJECTS}

This study was carried out at a healthy living center where overweight and obese individuals voluntarily participated in a supervised weight-loss program that incorporated exercise training. The study involved 17 adults classified as obese according to the World Health Organization (gender: 5 males and 12 females; ages: $48.06 \pm 10.94$ years; BMI: $\left.33.55 \pm 2.90 \mathrm{~kg} / \mathrm{m}^{2}\right)$ and 15 normal-weight healthy controls (gender: 4 males and 11 females; age: $44.33 \pm 8.51$ years; BMI: $22.58 \pm 1.31 \mathrm{~kg} / \mathrm{m}^{2}$ ). At the beginning of the study, obese adults not involved in any physical activity during the last six months were informed about the physical exercise program, and all of the participants were asked to complete a questionnaire to obtain background information about their general health status, medical history, and nutritional patterns. Participants with regular physical activity, suspicious pathological findings, recent illnesses, or injuries and those using drugs, cigarettes, alcohol, vitamins, and nutrients, which all might affect OS markers, were excluded from the study. The level of consumption of eggs, meat, vegetables, dairy products, fruits, and soft drinks was similar among the participants. The participants were asked to eat and drink as usual and were asked to not consume any antioxidant supplements during the study period. The study protocol was approved by the local ethics committee of the University of Harran (code: 17/06/01), and informed written consent was received from all study participants.

\section{EXERCISE TRAINING PROGRAM}

A twelve-week exercise training program was implemented with the obese adults in the form of brisk walking, as seen in Table I. The obese adults were instructed to walk at a pace of between 3.5 and $4.5 \mathrm{mph}$ for 60 minutes a day five times per week. Each exercise session consisted of a 10-minute warm-up, a 60-minute brisk walking, and a 10-minute cool-down. Professional trainers designed and implemented the brisk walking at an outdoor track. The optimal walking speed was adapted from guidelines provided by the Centers for Disease Control and Prevention (CDC 2015).

\section{BLOOD SAMPLING}

Venous blood samples were taken from the obese adults two times, one week before the initiation of the exercise training and a week after the training program was completed. Venous blood samples were taken from the control subjects at the start of the study only. For all parameters, all blood samples were collected in the morning following a minimum of 8 hours of overnight fasting. The collected blood samples were then centrifuged for 10 minutes at $1500 \times \mathrm{xg}$ rpm, and the separated serum was stored at $-86^{\circ} \mathrm{C}$ until the time when it was

TABLE I

Exercise training program.

Exercise training program (brisk walking)

\begin{tabular}{cccccc}
\hline Duration & Frequency & Walking time & Walking speed & Warm-up & Cool-down \\
\hline 12 & 5 & 60 & 3.5 to 4.5 & 10 & 10 \\
weeks & times / week & $\min /$ day & $\mathrm{mph}$ & $\min /$ day & $\mathrm{min} /$ day \\
\hline
\end{tabular}


analyzed. All of the parameters that we examined were studied from the same serum samples.

\section{THIOL/DISULPHIDE HOMEOSTASIS PARAMETERS}

The serum TDH parameters were examined using a new, automated measurement technique improved by Erel and Neselioglu (Erel and Neselioglu 2014). Briefly, the serum native thiol and total thiol levels were determined spectrophotometrically using Cobas c501 (Roche Diagnostics, Indianapolis, Indiana, USA). First, the serum native thiol levels were measured after a reaction with 5, 5'-dithiobis-2-nitrobenzoic acid (DTNB) without any previous processing. Secondly, to measure the total thiol levels, the dynamic disulphide bonds in the serum samples were reduced using sodium borohydride $\left(\mathrm{NaBH}_{4}\right)$ to form free functional thiol groups. Subsequently, formaldehyde was used to completely remove the unused $\mathrm{NaBH}_{4}$, and the total thiol groups including both the reduced and the native ones were measured following the reaction with DTNB. As the reduction of a disulphide bond generates two distinct thiol groups, the amount of dynamic disulphide bonds was calculated by determining half of the difference between the total thiol and the native thiol. In addition, the percentage ratios of disulphide/native thiol, disulphide/total thiol, and native thiol/total thiol were all calculated.

\section{STATISTICAL ANALYSIS}

Statistical analyses were conducted with SPSS for Windows version 22.0 software (IBM SPSS Inc, Chicago, IL, USA). The Shapiro Wilk test was employed to assess the normal distribution of data. Numerical variables with normal distribution were presented as mean \pm standard deviation, while those without normal distribution were expressed as median (interquartile range) values. Categorical variables were stated as number (n) and percentage (\%). Comparison of two-sample numerical variables was conducted using the
Unpaired Student's t-test and Mann-Whitney U test. To compare intragroup alterations over time (from baseline to after the exercise training), all dependent variables were examined with the Paired Student's t-test and Wilcoxon t-test. The Chi-square test was also used to compare categorical variables. Correlation between the numerical parameters was analyzed with Pearson correlation analysis. The confidence interval (CI) was accepted as 95\% throughout the analyses. A two-tailed $p$ value of $<0.05$ was considered statistically significant.

\section{RESULTS}

No statistically significant differences were observed based on gender, age, and serum albumin levels between the obese and control groups ( $p>$ 0.05 , for each). However, the BMI levels of the obese adults were significantly higher than those of the control group ( $p<0.001)$, as is illustrated in Table II.

Before the exercise training program began, it was observed that the serum native thiol and total thiol levels and the ratio of native thiol/total thiol were significantly lower in the obese group as compared to the control group ( $p=0.022, p=0.045$ and $p=0.007$, respectively). In contrast, the serum disulphide level and the ratios of disulphide/native thiol and disulphide/total thiol were significantly higher in the obese group as compared to the control group $(p=0.039, p=0.007$ and $p=0.007$, respectively). After the exercise training program was finished, it was observed that the serum native thiol level and the ratio of native thiol/total thiol were both significantly lower in the obese adults as compared to the normal-weight controls ( $p=0.041$ and $p=0.016$, respectively). However, the ratios of disulphide/native thiol and disulphide/total thiol were significantly higher in the obese adults as compared to the same ratios in the normal-weight controls ( $p=0.016$, for each), as is demonstrated in Table III and Figure 1. 
TABLE II

Demographic and laboratory parameters from the obese and control groups prior to the initiation of the exercise training.

\begin{tabular}{|c|c|c|c|}
\hline Variable & $\begin{array}{c}\text { Control group } \\
\quad(n=15)\end{array}$ & $\begin{array}{c}\text { Obesity group } \\
\quad(n=17)\end{array}$ & $p$-Value \\
\hline Age (years) & $44.33 \pm 8.51$ & $48.06 \pm 10.94$ & 0.296 \\
\hline Gender (male), n (\%) & $4[26.7]$ & $5[29.4]$ & 0.863 \\
\hline BMI $\left(\mathrm{kg} / \mathrm{m}^{2}\right)$ & $22.58 \pm 1.31$ & $33.55 \pm 2.90$ & $<0.001$ \\
\hline Albumin (g/dL) & $4.55 \pm 0.13$ & $4.53 \pm 0.12$ & 0.685 \\
\hline
\end{tabular}

Parameters were communicated as mean $\pm \mathrm{SD}$ and median [IQR]. SD: standard deviation; IQR: interquartile range.

TABLE III

The comparison of TDH parameters between the obese and control groups both prior to and after the completion of the exercise training program.

\begin{tabular}{|c|c|c|c|c|c|}
\hline \multirow[b]{2}{*}{ Variables } & \multirow[b]{2}{*}{$\begin{array}{l}\text { Control } \\
(n=15)\end{array}$} & \multicolumn{4}{|c|}{ Obesity group } \\
\hline & & $\begin{array}{c}\text { BETP } \\
(n=17)\end{array}$ & $\begin{array}{c}* p- \\
\text { Values }\end{array}$ & $\begin{array}{c}\text { AETP } \\
(n=17)\end{array}$ & ${ }^{*} p$-Values \\
\hline Native thiol $(\mu \mathrm{mol} / \mathrm{L})$ & $290 \pm 51$ & $248 \pm 48$ & 0.022 & $255 \pm 41$ & 0.041 \\
\hline Total thiol $(\mu \mathrm{mol} / \mathrm{L})$ & $326 \pm 51$ & $294 \pm 35$ & 0.045 & $297 \pm 38$ & 0.081 \\
\hline Disulfide $(\mu \mathrm{mol} / \mathrm{L})$ & $17.8 \pm 3.7$ & $22.9 \pm 8.4$ & 0.039 & $20.8 \pm 5.8$ & 0.096 \\
\hline$\%$ Disulfide/native thiol & $5.87[1.7]$ & $8.21[8.0]$ & 0.007 & $8.15[4.1]$ & 0.016 \\
\hline$\%$ Disulfide/total thiol & $5.25[1.4]$ & $7.05[5.6]$ & 0.007 & $7.0[3.0]$ & 0.016 \\
\hline$\%$ Native thiol/total thiol & $89.5[2.8]$ & $85.9[11.1]$ & 0.007 & $86.0[6.0]$ & 0.016 \\
\hline
\end{tabular}

Parameters were communicated as mean \pm SD or median [IQR]. SD: standard deviation; IQR: interquartile range; BETP: before exercise training program; AETP: after exercise training program.

* $p$-Values between control and obesity groups before exercise training.

* $p$-Values between control and obesity groups after exercise training.

In obese adults, even though the BMI was significantly diminished over time when comparing the measurements at the baseline and after the exercise training was over $(p<0.001)$, no important alteration was observed in the TDH parameters after the exercise training in comparison with the pre-exercise training measurements $(p>0.05$, for each), which can be seen in Table IV and Figure 1

The serum native thiol and the total thiol levels and the native thiol/total thiol ratio were all inversely correlated with BMI $(r=-0.627, p=$ $0.007 ; r=-0.595, p=0.012$; and $r=-0.603, p=$ 0.010 , respectively). On the other hand, there were significantly positive correlations between BMI and serum disulphide levels, disulphide/native thiol and disulphide/total thiol ratios $(r=0.544$, $p=0.024 ; r=0.601, p=0.011 ;$ and $r=0.603, p=$ 0.010 , respectively), which is illustrated in Table V. However, after twelve weeks of the exercise training program, no considerable correlation was observed between the TDH parameters and the BMI in the obese adults ( $p>0.05$, for each).

\section{DISCUSSION}

Although many studies have reported that both obesity (Da Silva Medeiros et al. 2015, Manna and Jain 2015, Matsuda and Shimomura 2013, Rupérez et al. 2014) and physical exercise (Bianchi and Ribisl 2015, Da Silva Medeiros et al. 2015) are significantly associated with OS, as far as we know, 

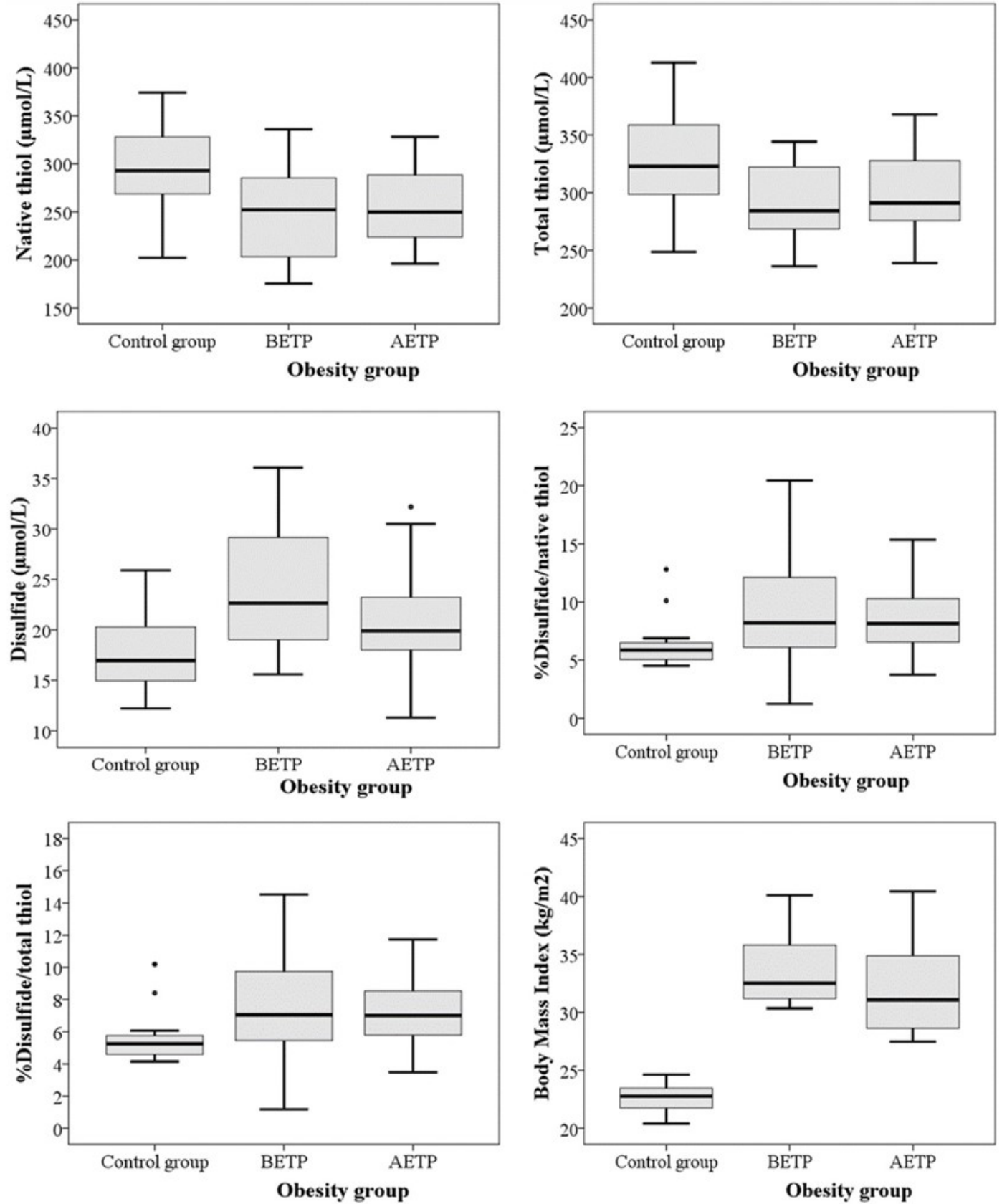

Figure 1 - The comparison of TDH and BMI parameters between the obese and control groups both prior to and after the completion of the exercise training program. BETP: before exercise training program; AETP: after exercise training program.

no previous study has investigated the influence of newly initiated exercise training on TDH, a novel OS marker, in obese adults. In this study, TDH was found to be significantly impaired, and this impairment was significantly associated with BMI in obese adults before they implemented the exercise training program. This impairment may be due to high oxidative stress caused by increased ROS production and dysregulated expression of inflammatory-related adipokines in enlarged adipocytes (Sakurai et al. 2017). Additionally, although BMI was significantly decreased in obese 
TABLE IV

The comparisons of albumin and TDH parameters in the obese group prior to and after the completion of the exercise training program.

\begin{tabular}{|c|c|c|c|}
\hline Variables & $\operatorname{BETP}(n=17)$ & $\operatorname{AETP}(n=17)$ & $p$-Values \\
\hline BMI $\left(\mathrm{kg} / \mathrm{m}^{2}\right)$ & $33.55 \pm 2.90$ & $31.84 \pm 3.87$ & 0.007 \\
\hline Albumin (g/dL) & $4.53 \pm 0.12$ & $4.52 \pm 0.17$ & 0.900 \\
\hline Native thiol $(\mu \mathrm{mol} / \mathrm{L})$ & $248 \pm 48$ & $256 \pm 41$ & 0.197 \\
\hline Total thiol $(\mu \mathrm{mol} / \mathrm{L})$ & $294 \pm 35$ & $297 \pm 38$ & 0.461 \\
\hline Disulfide $(\mu \mathrm{mol} / \mathrm{L})$ & $22.9 \pm 8.4$ & $20.8 \pm 5.8$ & 0.320 \\
\hline$\%$ Disulfide/native thiol & $8.21[8.0]$ & $8.15[4.1]$ & 0.193 \\
\hline \%Disulfide/total thiol & $7.05[5.6]$ & $7.0[3.0]$ & 0.210 \\
\hline$\%$ Native thiol/total thiol & $85.9[11.1]$ & $86.0[6.0]$ & 0.210 \\
\hline
\end{tabular}

Parameters were communicated as mean \pm SD and median [IQR]. SD: standard deviation; IQR: interquartile range; BETP: before exercise training program; AETP: after exercise training program.

TABLE V

The relationship between BMI and TDH parameters in obese adults prior to the initiation of the exercise training program.

\begin{tabular}{cccccccc}
\hline & Native thiol & Total thiol & Disulfide & $\begin{array}{c}\text { \% Disulfide / } \\
\text { native thiol }\end{array}$ & $\begin{array}{c}\text { \% Disulfide / } \\
\text { total thiol }\end{array}$ & $\begin{array}{c}\text { \% Native thiol / } \\
\text { total thiol }\end{array}$ \\
\hline \multirow{2}{*}{ BMI } & $\boldsymbol{r}$-Values & -0.627 & -0.595 & 0.544 & 0.601 & 0.603 & -0.603 \\
& $\boldsymbol{p}$-Values & 0.007 & 0.012 & 0.024 & 0.011 & 0.010 & 0.010 \\
\hline
\end{tabular}

adults after twelve weeks of exercise training during this investigation, no improvement was observed in the impaired TDH, which may be due to the excessive production of ROS in exercised skeletal muscle (Accattato et al. 2017).

Several studies carried out over the last few years have shown that obesity leads to increased ROS production and a weakness of the antioxidant defense systems, which ultimately results in OS (Da Silva Medeiros et al. 2015, Furukawa et al. 2004, Grattagliano et al. 2008, Manna and Jain 2015). Obesity induces OS for several biochemical reasons, such as superoxide production from NADPH oxidases, low antioxidant defense, oxidative phosphorylation, hyper-leptinemia, and chronic inflammation (Manna and Jain 2015, Savini et al. 2013, Serra et al. 2013). In this current study, in which we aimed to investigate OS by studying TDH parameters, the disulphide level and the ratios of disulphide/native thiol and disulphide/ total thiol were all significantly increased, but the native thiol and total thiol levels were considerably diminished in obese adults prior to the exercise training when compared with the control group. In addition, the serum disulphide levels, and the disulphide/native thiol and disulphide/total thiol ratios were positively correlated with BMI, but the native thiol and total thiol levels were inversely correlated with BMI in obese adults prior to the exercise training. These findings demonstrated that TDH was impaired in obese adults, which ultimately led to OS. As in this study, TDHimpairment was reported in obese adolescents with polycystic ovary syndrome by Ozler et al. (2016) and in obese children by Elmas et al. (2017). Any change in the thiol/disulphide balance in favor of an increasing disulphide formation causes physiological and structural pathologies in various 
organs and mechanisms by adversely affecting the ROS prevention mechanisms (Simsek et al. 2016). However, to the best of our knowledge, this is the first study to have investigated TDH in obese adults.

Obese individuals have higher ROS production in adipose tissue but controlling body weight through physical activity with adequate frequency and intensity and/or by caloric restriction may alleviate OS (Imayama et al. 2012). Since exercise training reduces the white adipose tissue mass, the expression of NADPH oxidase diminishes, and the expressions of antioxidant enzymes like superoxide dismutase and catalase increases, which relieve OS (Sakurai et al. 2017). On the other hand, as the amount of oxygen consumed in exercising skeletal muscle increases more than the amount of oxygen consumed at rest, ROS production in the mitochondria is also increased (Powers et al. 2014). Thus, physical exercise leading to OS causes muscle damage because of the oxidation of cell biomolecules such as proteins, lipids, and DNA (Powers et al. 2011, Sakurai et al. 2017). In the current study, although BMI for the obese adults was significantly decreased after twelve weeks of exercise training, no considerable alteration was found in the serum disulphide, native thiol, or the total thiol levels nor in the ratios of disulphide/ native thiol and disulphide/total thiol and native thiol/total thiol, most likely because of the increased ROS production in the exercised skeletal muscles. The fact that BMI was significantly reduced, but no improvement was observed in the TDH-impairment along with exercise training in obese adults indicates that newly initiated exercise training may actually increase ROS production in the skeletal muscles.

\section{LIMITATIONS}

The current study has some limitations. First, the number of participants is small. Secondly, our findings were not compared to other OS parameters, such as catalase, superoxide dismutase, glutathione peroxidase, malondialdehyde and 8-isoprostane. Thirdly, because we did not have the opportunity to measure the body fat mass separately, the results could not be compared to changes in body fat ratios. Finally, the effects of less or more severe physical activity and caloric restriction have not been investigated in the obese adults.

\section{CONCLUSION}

These findings suggest that $\mathrm{TDH}$, one of the prominent parameters of OS, was impaired, and this impairment was positively correlated with BMI in sedentary obese adults because of the higher ROS production in adipose tissue. However, no improvement was observed in the TDH-impairment despite significant decreases in BMI after twelve weeks of newly initiated exercise training since the ROS production was increased in exercised skeletal muscles. In conclusion, to prevent OS caused by exercised skeletal muscles in obese adults who begin a newly initiated exercise training to lose weight, potent antioxidants, such as ascorbic acid, alpha-tocopherol and polyphenols, can be added to their diets, and their exercise training program could be restructured (e.g.: stretching exercise can be added, and/or the intensity of the physical activity may be alleviated).

\section{AUTHOR CONTRIBUTIONS}

HC, MAE AND AZK; Designed the project, analyzed the data and wrote the manuscript. TK AND DSK; Performed the experiments and collected the relevant biological materials. OE; Performed the biochemical analysis and interpreted the data. CB; Designed the project and supervised the research. All authors discussed the results and approved the final version of the manuscript. 


\section{REFERENCES}

ACCATTATO F, GRECO M, PULLANO SA, CARE I, FIORILLO AS, PUJIA A, MONTALCINI T, FOTI DP, BRUNETTI A AND GULLETTA E. 2017. Effects of acute physical exercise on oxidative stress and inflammatory status in young, sedentary obese subjects. PLoS ONE 12: $\mathrm{e} 0178900$.

ATES I, KAPLAN M, YUKSEL M, MESE D, ALISIK M, EREL O, YILMAZ N AND GULER S. 2016. Determination of thiol/disulphide homeostasis in type 1 diabetes mellitus and the factors associated with thiol oxidation. Endocrine 51: 47-51.

ATES I, OZKAYAR N, ALTAY M, YILMAZ FM, TOPCUOGLU C, ALISIK M, EREL O AND DEDE F. 2015. Is disulphide/thiol ratio related to blood pressure in masked hypertension? Clin Exp Hypertens 38: 150-154.

BIANCHI VE AND RIBISL PM. 2015. Reactive oxygen species response to exercise training and weight loss in sedentary overweight and obese female adults. J Cardiopulm Rehabil Prev 35: 263-267.

CDC - CENTERS FOR DISEASE CONTROL AND PREVENTION. 2015. USA. General physical activities defined by level of intensity. http://www.cdc.gov/nccdphp/ dnpa/physical/pdf/PA_Intensity_table_2_1.pdf. (Accessed September 10, 2018).

DA SILVA MEDEIROS N, DE ABREU FG, COLATO AS, DE LEMOS LS, RAMIS TR, DORNELES GP, FUNCHAL C AND DANI C. 2015. Effects of concurrent training on oxidative stress and insulin resistance in obese individuals. Oxid Med Cell Longev 2015: 1-6.

DUGGAN C, DE DIEU TAPSOBA J, WANG C-Y, CAMPBELL KL, FOSTER-SCHUBERT K, GROSS MDA AND MCTIERNAN A. 2016. Dietary weight loss, exercise, and oxidative stress in postmenopausal women: A randomized controlled trial. J Cancer Prev 9: 835-843.

ELMAS B, KARACAN M, DERVISOGLU P, KOSECIK M, ISGUVEN SPA AND BAL C. 2017. Dynamic thiol/ disulphide homeostasis as a novel indicator of oxidative stress in obese children and its relationship with inflammatory-cardiovascular markers. Anatol J Cardiol 18: 361-369.

EMAMI SR, JAFARI M, HAGHSHENAS RA AND RAVASI A. 2016. Impact of eight weeks endurance training on biochemical parameters and obesity-induced oxidative stress in high fat diet-fed rats. J Exerc Nutrition Biochem 20: 29-35.

EREL O AND NESELIOGLU S. 2014. A novel and automated assay for thiol/disulphide homeostasis. Clin Biochem 47: 326-332.

FURUKAWA S, FUJITA T, SHUMABUKURO M, IWAKI M, YAMADA Y, MAKAJIMA Y, NAKAYAMA O, MAKISHIMA M, MATSUDA MA AND SHIMOMURA
I. 2004. Increased oxidative stress in obesity and its impact on metabolic syndrome. J Clin Invest 114: 1752-1761.

GRATTAGLIANO I, PALMIERI VO, PORTINCASA P, MOSCHETTAA AND PALASCIANO G. 2008. Oxidative stress-induced risk factors associated with the metabolic syndrome: a unifying hypothesis. J Nutr Biochem 19: 491504.

GUMUSYAYLA S, VURAL G, BEKTAS H, NESELIOGLU S, DENIZ O AND EREL O. 2016. A novel oxidative stress marker in migraine patients: dynamic thiol/disulphide homeostasis. Neurol Sci 37: 1311-1317.

HANIKOGLU F, HANIKOGLU A, KUCUKSAYAN E, ALISIK M, GOCENER AA, EREL O, BAYKARA M, CUOGHI A, TOMASI AND OZBEN T. 2016. Dynamic thiol/disulphide homeostasis before and after radical prostatectomy in patients with prostate cancer. Free Radic Res 50: 79-84.

HUANG CJ, MCALLISTER MJ, SLUSHER AL, WEBB HE, MOCK JT AND ACEVEDO EO. 2015. Obesity-related oxidative stress: The impact of physical activity and diet manipulation. Sports Med Open 1: 32-44.

IMAYAMA I, ULRICH CM, ALFANO CM, WANG C, XIAO L, WENER MH, CAMPBELL KL, DUGGAN C, FOSTER-SCHUBERT KE AND KONG A. 2012. Effects of a caloric restriction weight loss diet and exercise on inflammatory biomarkers in overweight/obese postmenopausal women: a randomized controlled trial. Clin Cancer Res 72: 2314-2326.

KRUK J AND DUCHNIK E. 2014. Oxidative stress and skin diseases: Possible role of physical activity. Asian Pac J Cancer Prev 15: 561-568.

KUNDI H, ATES I, KIZILTUNC E, CETIN M, CICEKCIOGLU H, NESELIOGLU S, EREL O AND ORNEK E. 2015. A novel oxidative stress marker in acute myocardial infarction; Thiol/disulphide homeostasis. Am J Emerg Med 33: 1567-1571.

MANNA P AND JAIN SK. 2015. Obesity, oxidative stress, adipose tissue dysfunction, and the associated health risks: Causes and therapeutic strategies. Metab Syndr Relat Disord 13: 423-444.

MARSEGLIA L, MANTI S, D’ANGELO G, NICOTERA A, PARISI E, DI ROSA G, GITTO E AND ARRIGO T. 2015. Oxidative stress in obesity: A critical component in human diseases. Int J Mol Sci 16: 378-400.

MATSUDA M AND SHIMOMURA I. 2013. Increased oxidative stress in obesity: Implications for metabolic syndrome, diabetes, hypertension, dyslipidemia, atherosclerosis, and cancer. Obes Res Clin Pract 7: 330341.

OZLER S, OZTAS E, TOKMAK A, ERGIN M, ISCI E, EREN F, PEHLIVAN S, NESELIOGLU S AND YILMAZ N. 2016. The association of thiol/disulphide homeostasis and lipid accumulation index with cardiovascular risk 
factors in overweight adolescents with polycystic ovary syndrome. Clin Endocrinol 84: 516-523.

POWERS SK, JI LL, KAVAZIS AN AND JACKSON MJ. 2014. Reactive oxygen species: Impact on skeletal muscle. Crit Rev Biomed Eng 1: 941-969.

POWERS SK, NELSON WB AND HUDSON MB. 2011. Exercise-induced oxidative stress in humans: Cause and consequences. Free Radic Biol Med Title 51: 942-950.

RUPÉREZ AI, GIL A AND AGUILERA CM. 2014. Genetics of oxidative stress in obesity. Int J Mol Sci 15: 3118-3144.

SAIKI S, SATO T, KOHZUKI M, KAMIMOTO M AND YOSIDA T. 2001. Changes in serum hypoxanthine levels by exercise in obese subjects. Metabolis 50: 627-630.

SAKURAI T, OGASAWARA J, SHIRATO K, IZAWA T, OH-ISHI S, ISHIBASHI Y, RADAK Z, OHNO H AND KIZAKI T. 2017. Exercise training attenuates the dysregulated expression of adipokines and oxidative stress in white adipose tissue. Oxid Med Cell Longev 2017: 1-12.

SAVINI I, CATANI MV, EVANGELISTA D, GASPERI V AND AVIGLIANO L. 2013. Obesity-associated oxidative stress: Strategies finalized to improve redox state. Int J Mol Sci 14: 10497-10538.

SERRA D, MERA P, MALANDRINO MI, MIR JF AND HERRERO L. 2013. Mitochondrial fatty acid oxidation in obesity. Antioxid Redox Signal 19: 269-284.
SIMSEK E, EREL O, BICER CK AND CARLIOGLU A. 2016. A novel method for determining the relation between nasal polyposis and oxidative stress: the thiol/disulphide homeostasis. Acta Otolaryngol 136: 1180-1183.

VESKOUKIS AS, GOUTIANOS G, PASCHALIS V, MARGARITELIS NV, TZIOURA A, DIPLA K, ZAFEIRIDIS A, VRABAS IS, KYPAROS A AND NIKOLAIDIS MG. 2016. The rat closely mimics oxidative stress and inflammation in humans after exercise but not after exercise combined with vitamin $\mathrm{C}$ administration. Eur J Appl Physiol 116: 791-804.

VINCENT HK, MORGAN JW AND VINCENT KR. 2004. Obesity exacerbates oxidative stress levels after acute exercise. Med Sci Sports Exerc 36: 772-779.

VINCENT HK, VINCENT KR, BOURGUIGNON C AND BRAITH RW. 2005. Obesity and postexercise oxidative stress in older women. Med Sci Sports Exerc 37: 213-219.

ZUBARIOGLU T, KIYKIM E, CANSEVER MS, NESELIOGLU S, AKTUGLU-ZEYBEK C AND EREL O. 2017. Evaluation of dynamic thiol/disulphide homeostasis as a novel indicator of oxidative stress in maple syrup urine disease patients under treatment. Metab Brain Dis 32: 179-184. 